\title{
Influence of rebar practice in the total cost of building construction projects: The case of Hawassa city, Ethiopia
}

\author{
Tariku Nigussie $^{1 *}$, M.K. Chandrasekar ${ }^{2}$ \\ ${ }^{I}$ Hawassa University, Institute of Technology, School of Construction Technology and Management, Hawassa, ETHIOPIA \\ ${ }^{2}$ Hawassa University, Institute of Technology, School of Civil Engineering, Hawassa, ETHIOPIA \\ * Corresponding Author: e-mail: arctare@gmail.com, Tel: +251-921-568080, \\ ORCID iD: https://orcid.org/0000-0002-9932-240X
}

\begin{abstract}
Rebar is one of the materials which is so scarce and highly expensive. The existing practices produce a large quantity of wastage; which contributes to the increment of the project cost. This study aimed to analyze the causes, extent, and remedies of steel wastages on the total costs of construction projects in Hawassa city. The study followed descriptive and analytical research designs. The cost estimated in the bill of quantity and the final cost after the provision of the steel with alterations was compared and the reasons for cost overrun were analyzed. The data were analyzed using Central value analysis, correlation and regression analysis using SPSS stat20, RebarWin7.97, ETABS2016. The percentage of the cost of steel wastage in total cost was found $1.43 \%$. The result of the study verdict that frequent design change and bare-benders skill gap contribute much to the material wastage, thus for the cost overrun of projects.
\end{abstract}

Keywords: Bending gain, cost overrun, detailing, rebar, redesign, steel, wastage

DOI: http://dx.doi.org/10.4314/ijest.v12i1.5

\section{Introduction}

Building construction is a long journey business that starts from the inception to the time of completion of projects. In the processes, it involves usage of different materials, appropriate technologies, heavy-duty machinery, schedules, energy and last but not least, uncertainties. Hence, the performance and successes construction project largely depends on its economic use of materials, staff efficiency, effective use of project period, and quality outputs. Now-a-days, the industry is boosting globally and consuming huge amounts of resources. Thus, managing wastage from a building construction project is a vital component of the optimum use of the limited resources to sustain the ongoing development. In this context, managing waste means minimizing the construction waste (Augustine, 2011; Cheng, 2014). However, the possibility of material wastage and its subsequent influence in the total cost of the building is quite common (Ameezden, 2014). In the industry, there are many causes of uncertainties for material wastage. One of the uncertainties is the improper ways of working with reinforcements that influencing the total cost of the construction projects (Ameh and Daniel, 2013).

In the construction industry, even though, steel is one of the costliest materials being used, there is less attention paid in using steel right from the estimating stage to the placement of reinforcement for concreting. Moreover, estimating the quantity of steel required meticulous calculations, guessing which leads to the use of a greater quantity of steel than required is practiced. Thus, to minimalize wastages, it needs assessing the optimum use of steel and to standardize the grades of steel at the country level to avail it for the different customers in the market.

Oversea, many researches have addressed the material wastage causes, remedies, its effect on the environment, and the cost of projects (Baytan, 2007). But, out of the different literatures referred, very few researches have dealt with wastage of steel. But, 
based on the experiences of practicing engineers steel wastage in building construction is around 5\% (Bayt, 2015). However, good practice and controlling system can reduce the percentage of waste of reinforcing steel (Fooster, 1972).

Wastage of steel in building construction was understood to happen at the procurement stage, material handling stage and at the design stage (Surve and Kulkarni, 2013). The use of grades of steel other than recommended in the design and design alterations may become common due to the market availability or non-availability of certain grades, which in turn can influence reworking and the unsafe use of the material (Al-Moghany, 2006). Though a safety factor is used in the design philosophy, additional safety measures could be employed by the designers by increasing some quantity or length of reinforcement. Thus, at the design stage, there are possibilities to use the excess quantity of steel than that is required. Good practice of producing and using a bar bending schedule (BBS) can minimize the wastage of steel (Chinanuwatwong, 2000; Afshar et al., 2008). But in many sites, BBS is not being supplied. Skilled and dedicated bar-benders really can optimize the use of steel by avoiding more numbers of cut bits, excess lengths left without cutting and alike.

In Ethiopia, most of the regions are highly prone to earthquake, hence detailing and scheduling of reinforcements should be made concerning the coded information (Worku, 2001). While in the field of practice, for low rise buildings of around 10 stories and less, which is common in Hawassa city, the rebar detailing is not found similar to the coded detailing procedures. The bar scheduling can show its effect over the economy as it concerns with measurements. Uncertainties are also possible to observe in the way of cutting, bending and positioning the reinforcements. Here, ignoring bending gains, not following the bar bending schedule for the easiness to exercise while bar bending could result in overuse of steel.

Hence, this study aimed to analyze the causes, extent of wastages and remedies, of steel in the construction sites of Hawassa city. The analysis is done on the use of rebar and its effect on the cost of building. Finally, the study suggests a solution and put recommendations to reduce the total cost of the project that happen due to improper use of rebar. In summary, this study addresses two important questions. 1) What are the factors that affect the cost overrun of steel used in a project? 2) How much is the percentage of steel wastage cost in the total cost of a project?

\section{Materials and Methods}

\subsection{Description of the study area}

The study was conducted in the building construction projects of Hawassa City. The beneficiaries are the construction participants and the building projects (low raised structures less than 10 storeys) as a whole of Hawassa City in particular, and the similar construction works throughout the country in general.

\subsection{Study design}

In this study, a descriptive and analytical type of research design was used. As the participants had similar features, a random sampling technique was adopted to select construction sites. The stratified sampling method was used to collect data to adjudge the effect of grade and make, as the respondents are going to be of different working groups like bar benders, supervisors, designers. To adjudge the effect of detailing, scheduling, bar bending, and cutting, a systematic sampling method were used as the samples are spread more evenly over the entire population. Random sampling technique was used to select a site for a case study to quantify how the different causes of misuse or wastage of steel influence the cost of the project.

2.3 Study methodology

Seventeen building construction sites with total floor area of the building between $500 \mathrm{~m}^{2}$ and $1500 \mathrm{~m}^{2}$ and with at least 3 storeys were selected within Hawassa City. Out of seventeen buildings considered for survey, 14 buildings were finally used for analysis of results as some uncertainty prevailed had influenced the consistency of the results. The construction activities in the sites so selected were at different stages like at the first storey level or and higher storey levels, in parallel working with finishing jobs.

2.4 Selection of study respondents

The study respondents were contractor and consultant managers, designers, bar benders, supervisors and quantity surveyors. Totally 5 respondents were selected in every site while 4 responses were considered for analysis as in some of the sites drop-outs were common.

\subsection{Tools and techniques of data collection}

The research designs used in this study were sampling design, observational design, and operational design. Data were collected through questionnaires, participative observations at sites and content analysis by checking the documents related to quantity surveying, detailing and rebar schedules. Questionnaire surveys helped the present research to assess different factors causing wastage or misuse of steel. In this survey, to know about design alterations due to market unavailability of certain diameter of bars, frequency of design alterations and effects on total cost, reasons for design alterations, effect of easiness to work with certain makes and its influence in total cost due to the bar benders delays etc. well-structured questions of open and closed-ended type were framed. Site observations were conducted with the participation of site members or engineers, to assess the effects of detailing, scheduling, cutting and bending of bars apart from the questionnaire. Sufficient information was collected through the already prepared documents available in the site and consultant's office related to the quantity surveying, checking of values, correctness of design, appropriate use of coded information for designs and quantity calculations were done as part of the content analysis method. 


\subsection{Stages proceeded in the research}

Questionnaire survey: The general ideas of the respondents on the rebar usage and wastage were gathered. This became the base for finalizing the factors causing wastages or misuse of steel and remedial measures that could be suggested.

- Site observations and interviews: This supplemented the confirmations to finalize the factors causing wastages or misuse of steel and how it happens in the real practice.

- A case study was undertaken to redesign a building and detail reinforcements and to find the percentage of cost increase due to improper use of steel.

2.7 Data management and analysis

The data such as questionnaire survey, interviews, and document analysis were collected. After editing, coding and classifying the data, correlation, and regression analysis were performed using SPSS stat20 software and Excel Spreadsheets. RebarWin 7.97 software was used for BBS preparation of existing design and redesigned works. ETABS 2016 software was used for analyzing the building chosen for the case study. Further, Excel sheets were used for redesigning components such as slab panels, beams, columns, and staircases.

\section{Results and Discussions}

Based on the questionnaire surveys and interviews obtained from the participants of the constructions, firstly, the factors responsible for the rebar misuse or wastage were assessed. Then one building was randomly selected out of the 14 samples and examined for excess use of steel than that is required. The contribution of steel to increase the total cost of the building was also determined.

\subsection{Influence of grade, make and purchase of rebars in wastage of steel}

From the analysis of the questionnaire survey and interviews, it was found that the bar benders prefer to use a lower grade of steel which could be easily bent. Figures 1 and 2 show the bar benders' grade preference and respondents' perspective over the market availability of different grades of steel, respectively. About 67\% of respondents have committed that working with S300 is easier while 13\% have felt to work with the design specification which is mentioned as neutral. $73 \%$ of respondents have answered that S300 is quite commonly available to purchase out of their experience, whereas the remaining percentage of respondents have committed that even S420 is also available in the local market. As rare cases, while higher-grade steel has to be used as per the design, design alterations have come into play to fulfill the easiness of the bar benders to use lower grade of steel. Moreover, in the market commonly available grade is S300. The strength values of rebars are not known to the dealers who sell due to the certificates of quality assurance not being supplied to the dealers. But these reasons have shown insignificant impact on the cost increase of steel.

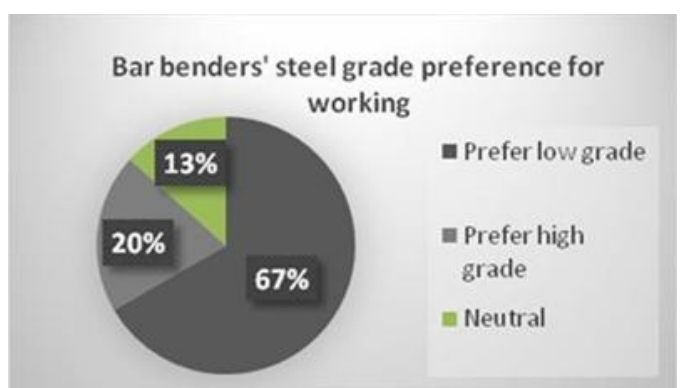

Figure 1: Bar benders' grade preference

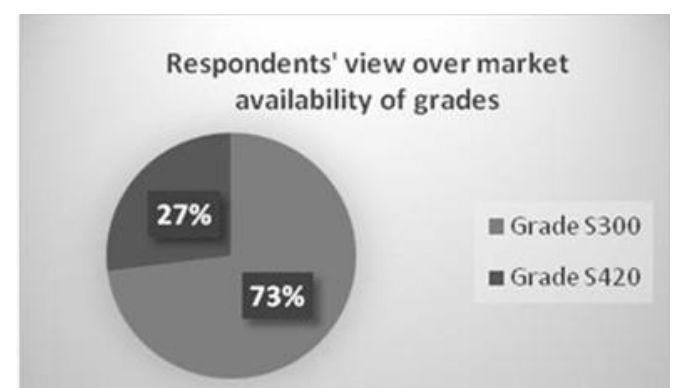

Figure 2: Market availability of grades

Table 1 shows the opinion of the respondents concerning to the procurement of steel. Likert scale was used to check the influences of particulars as given in the Table 1 .

Table 1: Influence of procurement of materials

\begin{tabular}{cllcccc}
\hline No. & \multicolumn{1}{c}{ Particulars } & $\mathbf{5}$ & $\mathbf{4}$ & $\mathbf{3}$ & $\mathbf{2}$ & $\mathbf{1}$ \\
\hline \multirow{2}{*}{1} & $\begin{array}{l}\text { Procuring of materials irrelevant to project requirements defined } \\
\text { on design documents }\end{array}$ & $16.67 \%$ & $73.33 \%$ & $6.67 \%$ & $3.33 \%$ & $0 \%$ \\
2 & Excess purchase due to errors in quantity calculations & $20 \%$ & $70 \%$ & $3.33 \%$ & $6.67 \%$ & $0 \%$ \\
3 & $\begin{array}{l}\text { Excess purchase due to deficiency of coordination between } \\
\text { purchase and construction crews }\end{array}$ & $16.67 \%$ & $76.66 \%$ & $0 \%$ & $6.67 \%$ & $0 \%$ \\
4 & $\begin{array}{l}\text { Purchasing lesser quantities than required } \\
5\end{array}$ & $\begin{array}{l}\text { Purchase of expensive material with high performance } \\
\text { 5=Very high 4= High 3= Moderate }\end{array}$ & 2= Low & 1 = very Low & & \\
\hline
\end{tabular}


$73 \%$ of the respondents reported that the purchase had been done other than that was used in the design. Also over ordering had happened due to mistakes in quantity surveying and due to lack of coordination between the construction crews. But fortunately, purchasing a higher grade of steel that is used in the design was committed to be of low percentages. Hence the analysis shows that money loss is found to happen due to quantifying and due to lack of co- ordination. Apart from the analysis by questionnaire and interviews, as given above, the strengths of different manufactured steel were checked by conducting tension tests on specimens, and the results are summarized in Table 2. The results show that the strength of the samples from all the manufacturers was adequate and satisfactory.

Table 2: Strength of different steel grade and make available in market

\begin{tabular}{cccccc}
\hline Grade & Make & $\begin{array}{c}\text { Diameter } \\
\mathbf{m m}\end{array}$ & $\begin{array}{c}\text { Weight } \\
\mathbf{K g} / \mathbf{m}\end{array}$ & $\begin{array}{c}\text { Yield strength } \\
\mathbf{N} / \mathbf{m m} \mathbf{2}\end{array}$ & $\begin{array}{c}\text { Ultimate strength } \\
\mathbf{N} / \mathbf{m m} \mathbf{2}\end{array}$ \\
\hline S300 & Turk & $12 \mathrm{~mm}$ & 0.888 & 319 & 463 \\
S420 & Turk & $12 \mathrm{~mm}$ & 0.889 & 432 & 549 \\
Grade40 & Akaki & $14 \mathrm{~mm}$ & 1.21 & 325 & 467 \\
Grade60 & Akaki & $16 \mathrm{~mm}$ & 1.577 & 436 & 547 \\
S300 & Zuquala & $12 \mathrm{~mm}$ & 0.889 & 315 & 459 \\
S300 & Apollo & $10 \mathrm{~mm}$ & 0.616 & 322 & 463 \\
S300 & Abissynia & $12 \mathrm{~mm}$ & 0.886 & 318 & 456 \\
\hline
\end{tabular}

3.2 Influence of cutting, bending, detailing and scheduling in wastage of steel

After the detailed investigation through questionnaire and interviews, the factors that were prominently being considered as causing the wastage/misuse of steel and the cost of steel were sorted out to be of 10 in numbers. In other words, analysis of results under this head was performed using 10-point scale. The factors are:-

1. Extending bars more than the required length or not following exactly BBS (Extending bars): Either in the BBS or structural design drawing, length of bars to be cut is specified. But the bar benders most often do not take care to optimize the use of $12 \mathrm{~m}$ long bars, as supplied from manufacturers, to cut for the definite requirement, without leaving short unusable pieces. Instead, there were extended bars more than the given length found in thesites.

2. Short unusable pieces produced after cutting \& left uncared (Short cut pieces): This could be another factor related to the first one, i.e. to leave some unusable short pieces after cutting the bars to the exact requirement as per the BBS or structural design drawing.

3. Non-optimized cutting of bars (Non-optimized cutting): This refers to the non-optimized cutting of $12 \mathrm{~m}$ long bars as supplied. This also can lead to unusable pieces and/or over sized pieces which can be used, but noteconomical.

4. Mistake in cutting or use of incorrect diameter of bars, thus reworking (mistake andrework)

5. Poor supervision by qualified engineer during cutting and bending (Poor supervision)

6. Structural design and detailing not to standard (Design, detail not to standard): This factor may influence the misuse of steel if the design parameters such as loading, load combinations, envelope effect are considered improperly and if the detailing provisions are not followed based on coded standard.

7. Bar bending schedule not properly supplied from design office. (BBS not supplied): If the BBS is not supplied from the design office, the bar benders use their own way of bending having some little guidance from the structural drawings. This can lead to erroneous length calculations that could be committed by the bar bender and in fabrication delay and sometimes unevenness in similar sort of fabrication requirements.

8. Bending gain not considered while detailing (Bend gain not used): When the bar is bent, there is an elongation of bar length. This elongation of length is called bending gain. While detailing, the designer's crew should consider this length as excess and the length of the bar to be bent can be cut to a lesser length than the required length, considering bend gain. If it is not considered, there is an excess quantity of steel that is used in the design.

9. Design alterations were more (More design alteration): If there are design alterations, there are possibilities of mismatch between the quantity calculated for BOQ and the quantity used at the end.

10. Poor usage of software for bar bending schedule preparation (Poor usage of software): If software is used for BBS, manual errors and there by some wastage of quantities can be avoided.

\subsubsection{Analysis based on mean standard deviation}

The points given by the respondents for different factors, as shown in Table 3, are based on both questionnaires and interviews. Based on mean values of responses from all the fourteen sites, if the factors are ranked, Excluding bending gain, detailing, BBS not been supplied, non-compliance of design and detailing some better standard and extending bars beyond come first, second, third and fourth, respectively. The factors beyond the fourth are not required. Even though the sites are different, the work culture was almost similar and the nature of responses was also similar. Hence, ranking by mean was also considered as one of the results. Moreover, from the above description of ranking, for the top ranking factors the standard deviation values were found to be very low such as $0.82,1.29,0.8$ and 1.44 while the mean values were as high as 8.54, 7.7, 7.18 and 5.75 respectively. This shows that the normal distribution was fairly closer and thus the responses were reliable. 


\subsubsection{Content analysis}

By the content analysis of documents collected from the various sites, the quantity of steel calculated in bill of quantity (BOQ) and the total quantity of steel used at the end of the projects were compared and the cost overrun in steel usage was calculatedas shown in Table 4. For all of the sites, the quantity of steel used up to the end of the projects exceeded the quantity of steel calculated in BOQ. For three of the sites, the quantities used were less than the quantities estimated in BOQ.Hence, to have the homogeneity and to consider the majority of uniqueness, only fourteen sites, which experienced cost overrun in steel usage were considered for analysis. Unexpectedly, the cost overrun was estimated to be as high as 8.81 in one of the sites. Hence, that site was selected to make the case study.

3.2.3 Correlation between individual causing factors and cost overrun

Having the percentage cost overrun and the response points of different factors causing the wastage of steel correlation analysis were performed to compare the effect of individual factors on cost overrun as shown in Tables 3 and 4, respectively.

Table 3: Influence of cutting, bending, detailing and scheduling in wastage of steel(Responses out of 10 points)

\begin{tabular}{|c|c|c|c|c|c|c|c|c|c|c|}
\hline $\begin{array}{c}\text { Buildings } \\
\downarrow\end{array}$ & 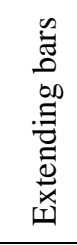 & 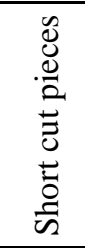 & 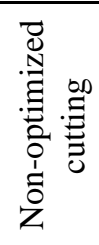 & 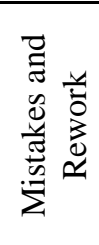 & 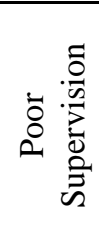 & 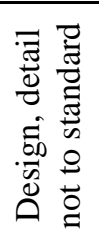 & 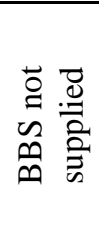 & 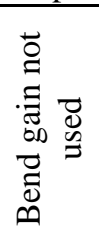 & 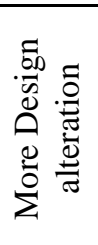 & 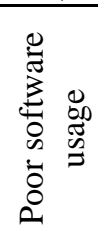 \\
\hline B1 & 9 & 7 & 7 & 5 & 3 & 9 & 9.5 & 9.75 & 7.75 & 5.75 \\
\hline B2 & 6 & 2.5 & 2 & 2.5 & 2.75 & 8 & 8.5 & 8.75 & 1.75 & 2.75 \\
\hline B3 & 4.75 & 2 & 1.5 & 1.5 & 2 & 7 & 6.75 & 8.5 & 1.75 & 2.5 \\
\hline B4 & 5 & 2 & 2.75 & 2.5 & 2.75 & 7.25 & 8.25 & 9.25 & 5.25 & 4 \\
\hline B5 & 5.5 & 2 & 2 & 2.75 & 2 & 6.75 & 7.25 & 9 & 1.75 & 2.5 \\
\hline B6 & 6 & 2.25 & 1.5 & 2.75 & 2 & 7 & 7.25 & 8.5 & 1.5 & 3.25 \\
\hline B7 & 8 & 5 & 3.75 & 4.25 & 3.25 & 8.25 & 9 & 9 & 4 & 4 \\
\hline B8 & 7.5 & 5 & 4 & 4 & 2.25 & 7 & 8.75 & 8.75 & 3.25 & 3 \\
\hline B9 & 5 & 2 & 2 & 1.75 & 1.75 & 6.75 & 6.75 & 8 & 1.75 & 2.5 \\
\hline B10 & 4.75 & 1.75 & 2 & 2.25 & 2.25 & 7 & 8.25 & 8.75 & 5 & 2.75 \\
\hline B11 & 5 & 2 & 1.5 & 1.75 & 1.75 & 6.5 & 7.75 & 8 & 3.75 & 2.25 \\
\hline B12 & 3.25 & 1.75 & 1.5 & 1.25 & 1.75 & 5.5 & 4 & 6.25 & 1.75 & 2 \\
\hline B13 & 5.25 & 3 & 2.75 & 2.25 & 2.75 & 7.25 & 8 & 9.25 & 2.25 & 2.5 \\
\hline B14 & 5.5 & 2.25 & 2.25 & 2 & 2.25 & 7.25 & 7.75 & 7.75 & 1.5 & 2.25 \\
\hline Mean & 5.75 & 2.89 & 2.61 & 2.61 & 2.32 & 7.18 & 7.7 & 8.54 & 3.07 & 3 \\
\hline Std Dev. & 1.44 & 1.54 & 1.44 & 1.06 & 0.48 & 0.8 & 1.29 & 0.82 & 1.81 & 0.96 \\
\hline
\end{tabular}

Table 4: Steel quantity estimated, used and cost overrun

\begin{tabular}{ccccccccc}
\hline \multirow{2}{*}{ Building } & \multirow{2}{*}{$\begin{array}{c}\text { Floor } \\
\text { area } \mathrm{m}^{2}\end{array}$} & $\begin{array}{c}\text { No. of } \\
\text { Storeys }\end{array}$ & $\begin{array}{c}\text { Total } \\
\text { floor } \\
\text { area } \mathrm{m}^{2}\end{array}$ & $\begin{array}{c}\text { On Bill of Quantity(BOQ) } \\
\text { Quntity of } \\
\text { steel in kg }\end{array}$ & $\begin{array}{c}\text { Cost of Steel } \\
\text { in Birr }\end{array}$ & $\begin{array}{c}\text { Quantity of } \\
\text { steel in kg }\end{array}$ & $\begin{array}{c}\text { Cost of } \\
\text { Steel in Birr }\end{array}$ & $\begin{array}{c}\text { \% of cost } \\
\text { Overrun }\end{array}$ \\
\hline B1 & 270 & 5 & 1620 & 49239.06 & 3693345.17 & 53575.34 & 4018602.8 & 8.81 \\
B2 & 463 & 4 & 2315 & 59768.37 & 4286897.14 & 62045.16 & 4450200.3 & 3.81 \\
B3 & 250 & 4 & 1000 & 44963.73 & 2674000.65 & 45653.09 & 2714997 & 1.53 \\
B4 & 335 & 4 & 1675 & 50218.23 & 3786526.34 & 52460.78 & 3955616.8 & 4.47 \\
B5 & 360 & 5 & 2160 & 55404.51 & 3961440.78 & 56945.82 & 4071645 & 2.78 \\
B6 & 437 & 4 & 2185 & 56236.63 & 3906270.48 & 57577.35 & 3999398.7 & 2.38 \\
B7 & 283 & 4 & 1132 & 34355.03 & 2311948.36 & 36731.33 & 2471863.3 & 6.92 \\
\hline B8 & 320 & 3 & 960 & 30426.26 & 2067840.21 & 32010.5 & 2175508.9 & 5.21 \\
B9 & 419 & 5 & 2514 & 62717.8 & 4829394.56 & 63934.57 & 4923088.3 & 1.94 \\
B10 & 346 & 4 & 1384 & 35032.71 & 2470088.83 & 36288.33 & 2558620.2 & 3.58 \\
B11 & 384 & 5 & 1920 & 52253.82 & 3876160.62 & 53880.81 & 3996849.9 & 3.11 \\
B12 & 445 & 6 & 2670 & 64714.74 & 4943130.76 & 65486.96 & 5002115.5 & 1.19 \\
B13 & 298 & 4 & 1490 & 36358.31 & 2656670.45 & 37430.9 & 2735043.7 & 2.95 \\
B14 & 378 & 5 & 1890 & 52748.58 & 3853030.99 & 53750.36 & 3926206.2 & 1.9 \\
\hline
\end{tabular}


Table 5 shows the correlation of cost overrun percentage in one of the factors, extending bars. Similarly, correlations of cost overrun percentage in other wastage causing factors were also performed, and the coefficient of correlation, ' $r$ ', values are shown in Table 6.

Table 5: Correlation between cost overrun percentage and the causing factor, extending bars

\begin{tabular}{|c|c|c|c|c|c|c|}
\hline Buildings & $\mathrm{X}$ & $\mathrm{Y}$ & $\mathrm{XY}$ & $\mathrm{X}^{2}$ & $\mathrm{Y}^{2}$ & \\
\hline B1 & 8.81 & 9 & 79.26 & 77.56 & 81 & \\
\hline B2 & 3.81 & 6 & 22.86 & 14.51 & 36 & $\mathrm{X}=\%$ cost overrun \\
\hline B3 & 1.53 & 4.75 & 7.28 & 2.35 & 22.56 & \\
\hline B4 & 4.47 & 5 & 22.33 & 19.94 & 25 & $\mathrm{Y}=$ Points obtained in 10 point scale for \\
\hline B5 & 2.78 & 5.5 & 15.3 & 7.74 & 30.25 & the considered factor, Extending bars \\
\hline B6 & 2.38 & 6 & 14.3 & 5.68 & 36 & more than the required length/not \\
\hline B7 & 6.92 & 8 & 55.34 & 47.84 & 64 & following BBS \\
\hline B8 & 5.21 & 7.5 & 39.05 & 27.11 & 56.25 & \\
\hline B9 & 1.94 & 5 & 9.7 & 3.76 & 25 & \\
\hline B10 & 3.58 & 4.75 & 17.02 & 12.85 & 22.56 & No of samples 'n' $=14$ \\
\hline B11 & 3.11 & 5 & 15.57 & 9.69 & 25 & Correlation \\
\hline B12 & 1.19 & 3.25 & 3.88 & 1.42 & 10.56 & Coefficient ' $r$ ' $=0.88$ \\
\hline B13 & 2.95 & 5.25 & 15.49 & 8.7 & 27.56 & \\
\hline B14 & 1.9 & 5.5 & 10.45 & 3.61 & 30.25 & \\
\hline$\Sigma$ & 50.58 & 80.5 & 327.82 & 242.77 & 492 & \\
\hline
\end{tabular}

For most of the factors that explain positive correlation between cost overrun occurred and the factors identified as responsible for such cost overrun the correlation coefficient ' $r$ ' values were found to be above 0.8 , as indicated in Table 6 . For a few of the factors such as poor supervision, BBS not been supplied, bend gain not used, and design alterations. The correlation coefficient is between 0.6 to 0.8 which could be considered medium positive correlation. Hence for the samples and responses to be wholesome the result of correlation was found to be satisfactory as similar to (Koshy and Apte, 2012). Thus, the ranking factors based on arithmetic mean can be considered as the major influencing factors for the cost overrun.

Table 6: Co-efficient of correlation ' $r$ ' values for different factors influencing cost overrun.

\begin{tabular}{|c|c|c|c|c|c|c|c|c|c|c|}
\hline Factors & 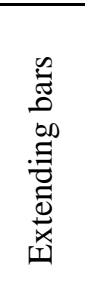 & 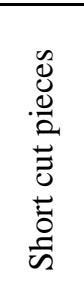 & 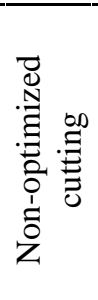 & 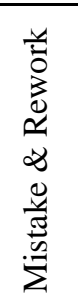 & 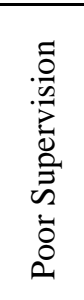 & 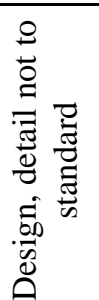 & 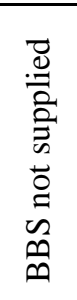 & 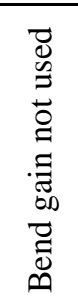 & 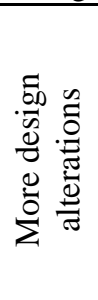 & 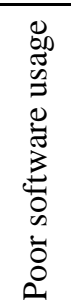 \\
\hline 'r' & 0.88 & 0.89 & 0.9 & 0.93 & 0.78 & 0.81 & 0.78 & 0.68 & 0.82 & 0.89 \\
\hline
\end{tabular}

\subsubsection{Regression between individual causing factors and cost overrun}

Regression analysis was conducted between the dependent variable (i.e. the cost overrun) and the independent variables (i.e. the factors responsible for cost overrun). The estimated value of cost overrun $\left(\mathrm{X}^{\wedge}\right)$ was found to be very close to the actual values of cost overrun $(\mathrm{X})$ thereby the analysis expressed that the factors have close relation with causes for the cost overrun. For example, Table 7 shows the regression analysis between cost overrun percentage and the causing factor, extending bars wherein $\mathrm{X}^{\wedge}$ values were found to be close to corresponding $\mathrm{X}$ values. The standard error and significance were observed as shown in Table 8. The standard error in the regression line plot for the different causing factors was between 0.77 and 1.53 which are very low and acceptable values when compared to the mean value. Significance values for all the factors were too small like 0.0, which shows that the regression line can be linear without 0 -degree inclination. Figure 3 shows the regression line drawn for one of the causing factors, i.e. extending bars and this proves that the significance and $\mathrm{X}^{\wedge}$ values can be reliable values. Thus, the relation between the dependent and independent variables is considered to be strong.

Table 7: Regression between cost overrun percentage and the causing factor, extending bars 


\begin{tabular}{|c|c|c|c|c|c|c|c|}
\hline$X^{\wedge}$ & $X$ & $Y$ & $X Y$ & $\mathrm{X}^{2}$ & $\mathrm{Y}^{2}$ & $\left(\mathrm{X}-\mathrm{X}^{\wedge}\right)^{2}$ & \\
\hline 7.74 & 8.81 & 9 & 79.26 & 77.56 & 81 & 1.14 & $\mathrm{n}=14$ \\
\hline 3.93 & 3.81 & 6 & 22.86 & 14.51 & 36 & 0.01 & $\mathrm{r}=0.88$ \\
\hline 2.34 & 1.53 & 4.75 & 7.28 & 2.35 & 22.56 & 0.66 & $A=60$ \\
\hline 2.66 & 4.47 & 5 & 22.33 & 19.94 & 25 & 3.25 & $B=29.13$ \\
\hline 3.3 & 2.78 & 5.5 & 15.3 & 7.74 & 30.25 & 0.26 & $C=36.96$ \\
\hline 3.93 & 2.38 & 6 & 14.3 & 5.68 & 36 & 2.39 & $\mathrm{~b}=1.27$ \\
\hline 6.47 & 6.92 & 8 & 55.34 & 47.84 & 64 & 0.2 & $a=-3.68$ \\
\hline 5.83 & 5.21 & 7.5 & 39.05 & 27.11 & 56.25 & 0.39 & Std Error=0.97 \\
\hline 2.66 & 1.94 & 5 & 9.7 & 3.76 & 25 & 0.52 & \multirow{8}{*}{$\begin{array}{l}\mathrm{X}=\% \text { cost overrun } \\
\mathrm{Y}=\text { Points obtained in } 10 \\
\text { point scale for the } \\
\text { considered factor, } \\
\text { Extending bars more } \\
\text { than the required length } \\
\text { or not following BBS }\end{array}$} \\
\hline 2.34 & 3.58 & 4.75 & 17.02 & 12.85 & 22.56 & 1.54 & \\
\hline 2.66 & 3.11 & 5 & 15.57 & 9.69 & 25 & 0.2 & \\
\hline 0.44 & 1.19 & 3.25 & 3.88 & 1.42 & 10.56 & 0.57 & \\
\hline 2.98 & 2.95 & 5.25 & 15.49 & 8.7 & 27.56 & 0 & \\
\hline 3.3 & 1.9 & 5.5 & 10.45 & 3.61 & 30.25 & 1.95 & \\
\hline$\Sigma$ & 50.58 & 80.5 & 327.82 & 242.77 & 492 & 13.1 & \\
\hline MEAN & 3.61 & 5.75 & & & & & \\
\hline
\end{tabular}

Table 8: Standard error and significance of different causing factors by regression

\begin{tabular}{|c|c|c|c|c|c|c|c|c|c|c|}
\hline Factors & 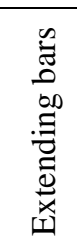 & 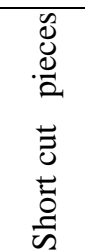 & 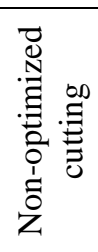 & 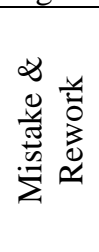 & 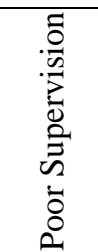 & 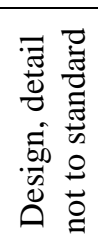 & 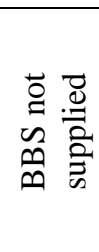 & 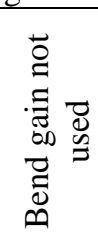 & 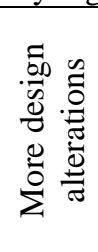 & 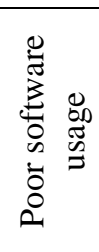 \\
\hline Std. Error & 0.97 & 0.93 & 0.89 & 0.77 & 1.3 & 1.2 & 1.3 & 1.5 & 1.18 & 0.94 \\
\hline $\mathrm{Sig}$ & 0 & 0 & 0 & 0 & 0.001 & 0 & 0.001 & 0.004 & 0 & 0 \\
\hline
\end{tabular}

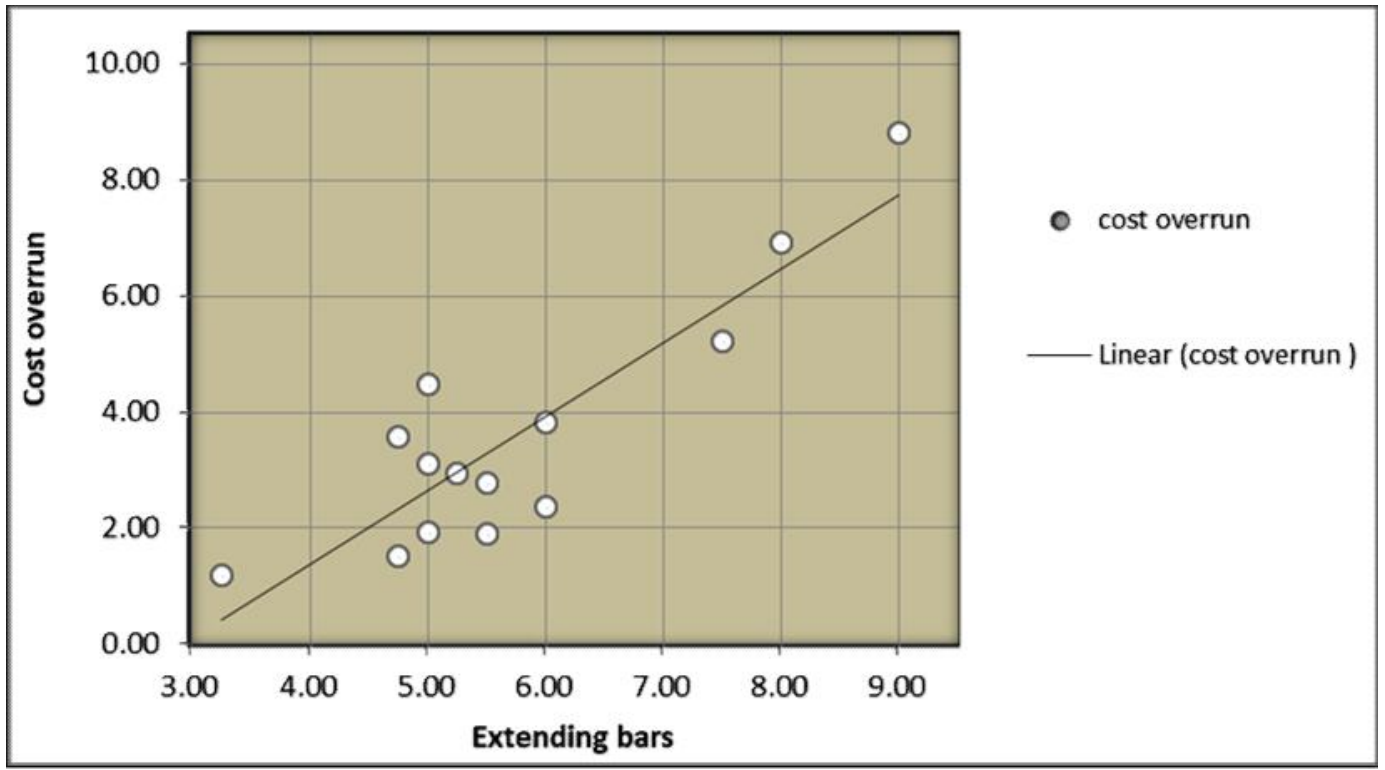

Figure 3: Regression line between cost overrun and extending bars beyond requirement

3.3 Case study

Based on the discussions made in section 3.2, the factors responsible for the wrong ways of using reinforcing steel in building constructions were highly concentrated in the part of designing and detailing. Hence, out of the fourteen, that experienced the 
greatest cost overrun in steel usage, the building designated as B1was selected for a case study. The particulars of the building selected are as follows.

$$
\text { Building build-up area: } 270 \mathrm{~m}^{2} \text { Number of story: } 5 \text { Building purpose: Hospital. }
$$

While checking the drawings, it was found that the provisions such as stirrup spacing to be maintained as needed in different sections, curtailments of beam bars, economical ways of bar cuttings and use of different diameters of bars to satisfy the area of steel required to its closer value, were not exactly made, that leads to excess quantity of steel to be used. Having found all these types of handicaps, the structure was modeled and analyzed by ETABS and re-designed according to be EBCS provisions. The redesigned quantities were a little different from that of the original design. The reason was found to be that there was some mismatch with the loads taken against the actual occupancy type used at last. That means, there were some changes in occupancy type, which is expected to be avoided during the building construction. In the site, it was also observed that the bar fabricating team provided extra lengths un-cut and the bar bending schedule did not consider bending gains.

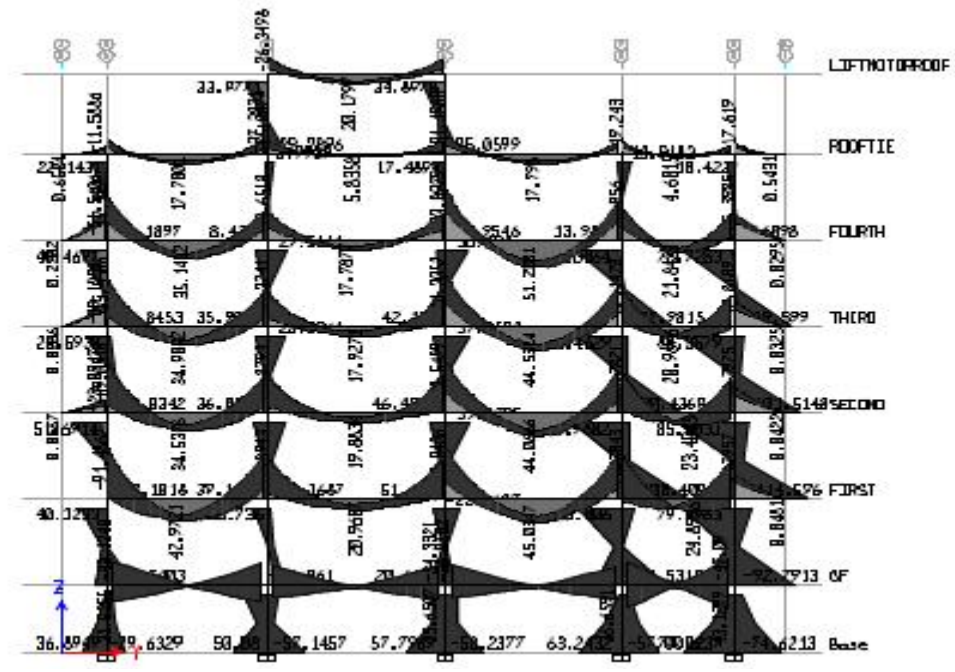

Figure 4: Redesigned ETABS 3D-model

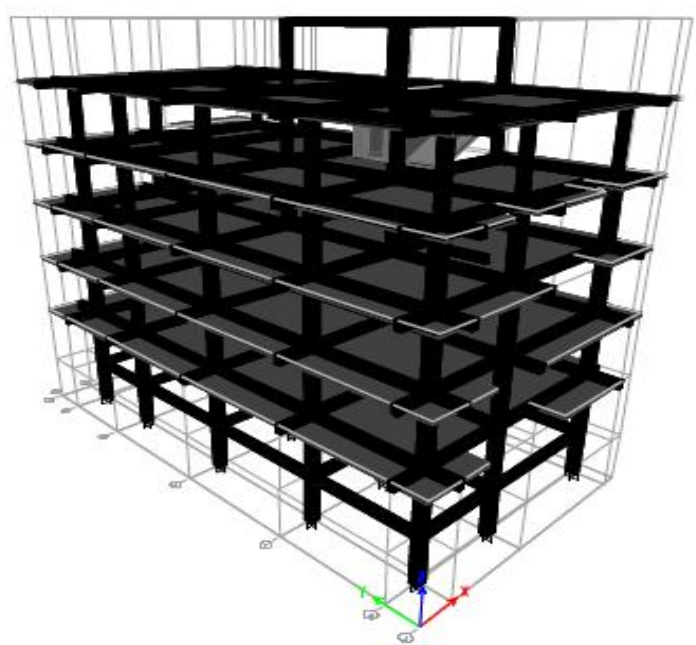

Figure 5: Bending moments in a critical frame 


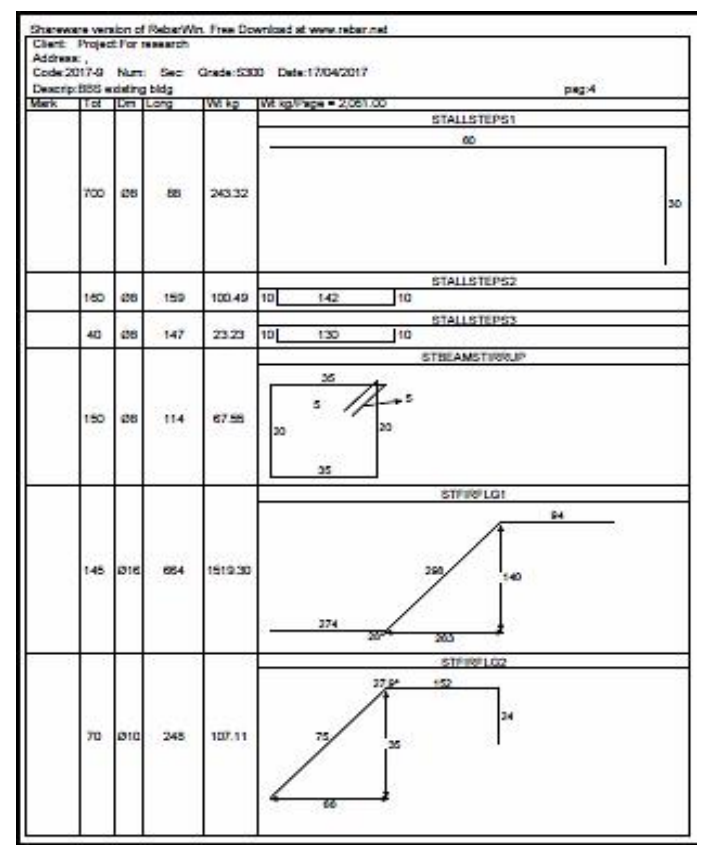

Figure 6: BBS output from Rebarwin software

Figure 4 shows the 3D model of the building under a case study that was redesigned using ETABS whereas, Figure 5 shows the ETABS output of bending moment diagram for one of the critical frame having greater values of bending moments after the analysis. The structural design of all the components was done using Excel templates, and the BBS was produced by RebarWin7.97 software. Figure 6 shows a part of the output of BBS from RebarWin.

The wastages that occurred due to uncertainty in design and detailing were sorted out as follows.

1. Stirrups spacing did not vary based on the value of shear to be taken at different locations of beams. In longer beams like $6.1 \mathrm{~m}, 5.5 \mathrm{~m}$ and $5 \mathrm{~m}$ spans definitely there were zones of minimum shear reinforcement requirement while the spacing provided in those regions did also not vary. As per the first design, $8 \mathrm{~mm}$ diameter stirrups were used at $180 \mathrm{~mm}$ spacing, for all the beams throughout their lengths. While redesigned it was found that cost reduction is possible through proper spacing provisions of stirrups.

2. For the ground floor slabs, the spacing of $8 \mathrm{~mm}$ diameter reinforcements provided was $180 \mathrm{~mm}$ center to center. However, as the slab panels rest over the ground, the minimum reinforcement requirement based on the provision such as 'spacing equal to $2 *$ thickness of slab or $350 \mathrm{~mm}$ whichever is less' as prescribed in EBCS2 may be provided. Hence, considering this rule, for $125 \mathrm{~mm}$ thick slab, the spacing of reinforcements in both directions was changed to $250 \mathrm{~mm}$ which considerably affected cost reduction.

3. Some of the reinforcement spacing in floor slabs were increased based on the spacing requirement for bending moment to resist. As the loads on slab panels were taken a bit high, in the actual design, this adjustment was required when redesigned.

4. In beam and column designs, combinations of at least two different diameters of rods were used in redesign based on area of steel required at certain section whereas, for all beams only $16 \mathrm{~mm}$ diameter rods were used in the original design and for most parts of the column, it was $20 \mathrm{~mm}$ diameter rods. Combinations of different diameters of rods to meet the area of steel required at a section very closely proved to be economical to some extent.

In the site visits, observations and measurements, during reinforcement cutting and bending operations, wastage of steel were observed such as:-

1. While the drawings show 135 degree bending of hooks for stirrups, the bar benders bend only for 90 degrees, with a greater hook length as indicated in Figure 7. The hook lengths were almost half of the side length of a stirrup.

2. In slabs and beams, excess lengths were left uncared and uncut, which increases substantially the quantity of steel used as indicated in Figure 8 that shows the uncut bottom reinforcements that pass through a joint. Thus the reinforcement cluster could hinder the concrete placement too.

3. Quite manifestly, laps with excess lengths were found and were measured to quantify the wastage of steel.

4. Bending gain was not considered in detailing and on the site. 


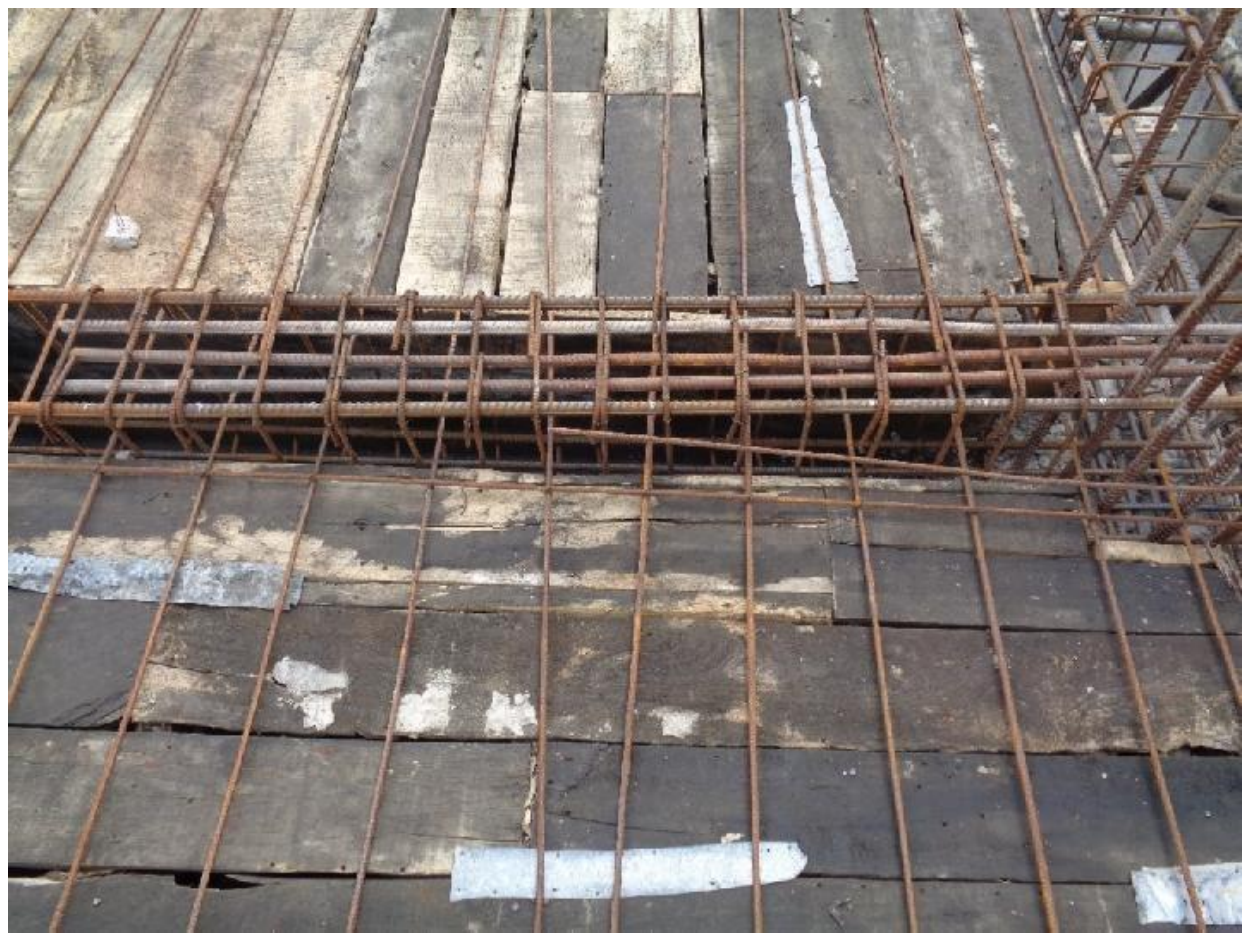

Figure 7: 90-degree bends in stirrups with greater hook length

Table 9 shows the wastages of steel in kg and in birr as calculated comparing original design detailing and BBS with the redesign and BBS produced after redesigning. The wastages due to cutting and bending were calculated by site calculations and measurements. Bending gain difference was obtained by RebarWin software. Having calculated the wastage in birr, the percentage wastage of steel in total cost of the project was found to be $1.43 \%$.

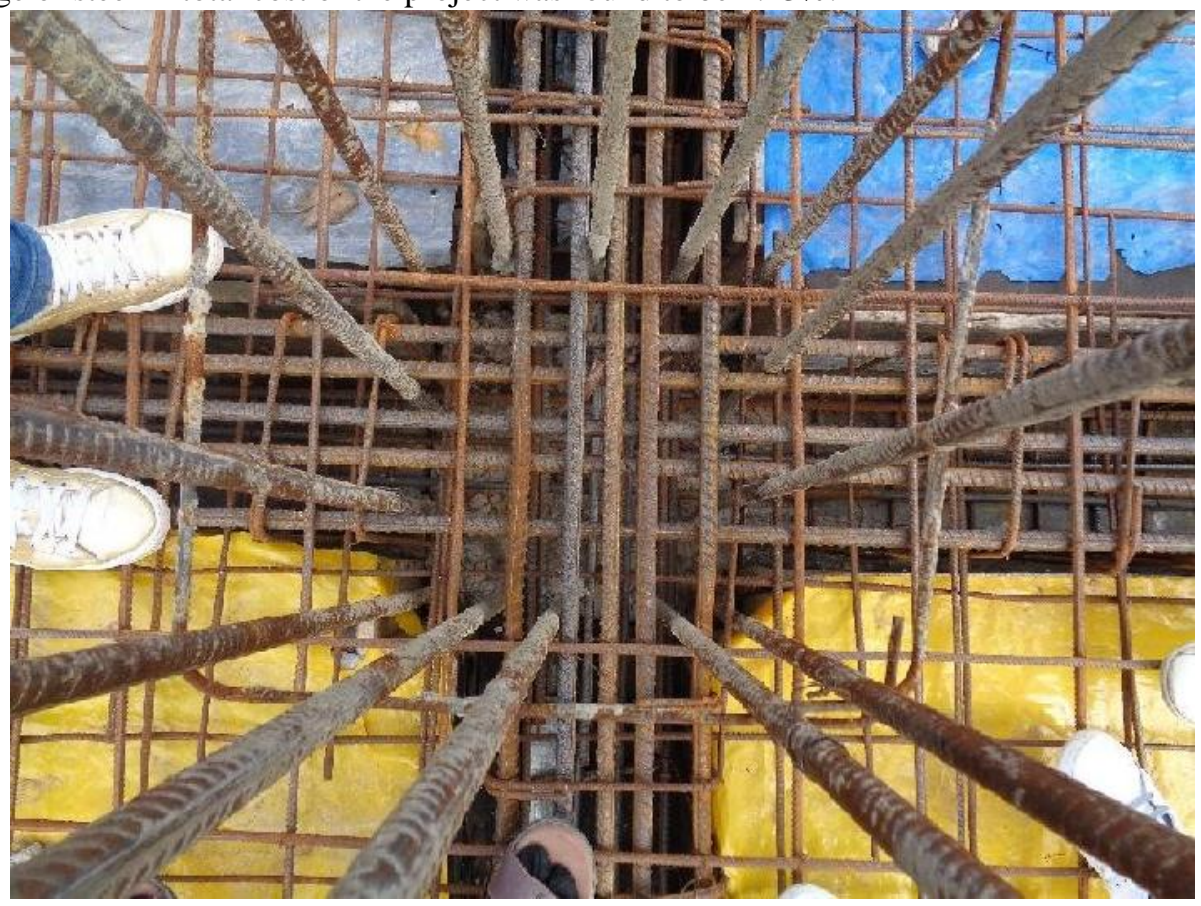

Figure 8: Rebar cluster in a joint, where bottom reinforcements were uncut 
Table 9: Calculation of wastage in steel due to design, detailing, cutting and bending

\begin{tabular}{|c|c|c|c|c|}
\hline Particulars & $\begin{array}{l}\text { Wastage of } \\
\text { steel in } \mathrm{kg}\end{array}$ & Cost/kg & $\begin{array}{l}\text { Wastage } \\
\text { in Birr }\end{array}$ & $\begin{array}{c}\% \\
\text { wastage in } \\
\text { total cost }\end{array}$ \\
\hline \multicolumn{5}{|l|}{ Wastage based on Design and detailing } \\
\hline Stirrups \& ties without considering minimum requirements & 71.1 & 33.4 & 2374.74 & 0.025 \\
\hline Ground floor slab rebars without minimum steel requirement & 158.63 & 33.4 & 5298.31 & 0.056 \\
\hline Slab reinforcement spacing alteration & 643.2 & 33.4 & 21482.81 & 0.226 \\
\hline $\begin{array}{l}\text { Without combining } 12 \text { and } 14 \text { dia bars to meet the very near } \\
\text { about value of } \mathrm{A}_{\mathrm{st}} \text { required. }\end{array}$ & 174.62 & 33.4 & 5832.34 & 0.061 \\
\hline $\begin{array}{l}\text { Without combining } 14 \text { and } 16 \text { dia bars to meet the very near } \\
\text { about value of } A_{\text {st }} \text { required. }\end{array}$ & 1635.66 & 33.4 & 54631.03 & 0.574 \\
\hline Changing $20 \mathrm{~mm}$ dia bars to 16 dia bars based on $\mathrm{A}_{\mathrm{st}}$ required & 375.94 & 33.4 & 12556.52 & 0.132 \\
\hline Changing $24 \mathrm{~mm}$ dia bars to 20 dia bars based on $\mathrm{A}_{\mathrm{st}}$ required & 287.09 & 37.55 & 10780.27 & 0.113 \\
\hline Wastage based on Cutting and bending & & & & 0 \\
\hline Stirrup bending with 90 deg hook & 149.41 & 33.4 & 4990.25 & 0.052 \\
\hline Excess length left without cutting & 237.5 & 33.4 & 7932.5 & 0.083 \\
\hline \multirow[t]{3}{*}{ Due to bending gain not considered } & 310.4 & 33.4 & 10367.36 & 0.109 \\
\hline & 4043.55 & & 136246.12 & 1.43 \\
\hline & $\begin{array}{c}9509576.63 \\
136246.12 \\
1.43\end{array}$ & & & \\
\hline
\end{tabular}

\section{Conclusion}

As most of the buildings under the study were private buildings, the designers, consultants, and contractors seemed to be paying more attention to safety and serviceability more than the concepts of waste minimization. From the questionnaire survey, it was found that the influence of cutting and bending in the total cost of the building was mainly due to extending bars beyond the required length. The same was found to be true from the results obtained from the case study. The unwanted lengths were left uncut or cutting was done with excess lengths, as the case may be, with different types of reinforcements such as in stirrups, longitudinal bars, laps, and hooks. The cost incurred from wastage due to excess provision of steel by providing 90-degree hooks instead of 135degree hooks for stirrups and by uncut excess lengths in birr was about 12922.75 which becomes $0.14 \%$ of the total cost of the building.

The influence of detailing and scheduling played a major role in increasing the effect of misuse or wastage of steel on the total cost of the project. The factors such as code provisions not followed while detailing, bar bending schedule not supplied to the bar benders and bending gain not considered while detailing and bar schedules were found to be dominant according to questionnaire and interviews. In the case study, wastage in steel was found to occur due to the incorrect provision of stirrup spacing, a spacing of ground floor slab reinforcements, use of the same diameter of rod for all the beams and not considering the bending gain. The percentage of wastage of steel in total cost amounted to $1.43 \%$. As far as steel is concerned, this is a very low and acceptable percentage of waste in the total cost of the building.

\section{Acknowledgment}

The authors wish to acknowledge all the professionals who contributed to this work. We would like to thank the Office of Research and Technology Transfer, Institute of Technology, Hawassa University for the financial support and opportunity to finalize this paper. We also give special thanks to Dr. Tesfaye Bayou, for his extensive follow-up, support, and guidance.

\section{References}

Afshar A, Amiri H, Eshtehardian E, 2008. An Improved Linear Programming Model For One-Dimensional Cutting Stock Problem., in: First International Conference on Construction in Developing Countries (ICCIDC-I). Advancing and Integrating Construction Education, Research \& Practice, August 4-5.Presented at the First International Conference on Construction In Developing Countries, Karachi, Pakistan.

Al-Moghany, S.S., 2006, Managing and minimizing construction waste in Gaza strip (M.Sc. thesis).Islamic University of Gaza, Palestine.

Ameezden R., 2014, Materials wastage on construction sites: Identification of major causes, Journal of Built Environment, Sri Lanka, Vol. 4, pp. 35-41. 
Ameh O.J., Daniel E.I., 2013. Professionals' views of material wastage on construction sites and cost overruns, Organization, Technology and Management in Construction: An International Journal, Vol. 5, pp. 747-757.

Augustine, 2011. Managing waste and cost in the construction industry: A case study of the road construction industry (MBA thesis). Kwame Nkrumah University of Science and Technology, Ghana.

Bayt, 2015. What is the wastage ratio for steel bars at site? [WWW Document]. URL https://specialties.bayt.com/en/specialties/q/70310/what-is-the-wastage-ratio-for-steel-bars-at-site/(Accessed on 25 June 2015) (accessed 11.16.19).

Baytan, M., 2007.Origins and Magnitude of Waste in the Turkish Construction Industry (PhD Thesis).MSc. Thesis, Middle East Technical University, Turkey.

Chinanuwatwong S., 2000. Reducing waste from cutting reinforcing steel in construction projects, Kasetsart Journal of Natural Sciences, Vol. 34, pp. 526-535

Cheng K.J., Mydin M.A.O., 2014. Best practice of construction waste management and minimization, Annals of the "Eftimie Murgu" University Resident, XXI Year, Vol. 21, No. 1, pp. 72-84.

Fooster, N, 1972. Construction Estimate from Take off to Bid. Mc-Graw Hill, New York PP. 209.

Koshy R, Apte E M R., 2012. Waste minimization of construction materials on a bridge site (Cement and Reinforcing steel). International Journal of Engineering and Innovative Technology, Vol. 2, pp. 6-14.

Surve R.B., Kulkarni S.S., 2013, Construction waste reduction - A case study, International Journal of Engineering Research and Technology, Vol. 2, pp. 870-875.

Worku, A., 2001, Comparison of seismic provisions of EBCS 8 and current major building codes pertinent to the equivalent static force analysis, Zede Journal of the Ethiopian Engineers and Architects, Vol. 18, pp. 11-25.

Received August 2019

Accepted January 2020

Final acceptance in revised form January 2020 